Chen X, Kontonikas A \& Montagnoli A (2012) Asset prices, credit and the business cycle, Economics Letters, 117 (3), pp. 857-861.

This is the peer reviewed version of this article

NOTICE: this is the author's version of a work that was accepted for publication in Economics Letters. Changes resulting from the publishing process, such as peer review, editing, corrections, structural formatting, and other quality control mechanisms may not be reflected in this document. Changes may have been made to this work since it was submitted for publication. A definitive version was subsequently published in Economics Letters, [VOL 117, ISS 3 (2012)] DOI: http://dx.doi.org/10.1016/j.econlet.2012.08.040 


\title{
Asset Prices, Credit and the Business Cycle*
}

\author{
${\text { Xiaoshan } \text { Chen }^{\S} \quad \text { Alexandros Kontonikas }}^{\dagger} \quad$ Alberto Montagnoli ${ }^{\ddagger}$
}

August, 2012

\begin{abstract}
This paper uses the multivariate unobserved components model with phase shifts to analyse the interaction of interest rates, output, asset prices and credit in the US. We find close linkages amongst cyclical fluctuations in the variables.

Keywords: Asset Prices, Credit, Business Cycles, Multivariate Unobserved Components Models. JEL classification: C32, E32, E44, E51, G0.
\end{abstract}

*We would like to thank Dimitris Korobilis, Campbell Leith, Charles Nolan and John Tsoukalas for their helpful comments and suggestions. Any remaining errors are sole responsibility of the authors.

${ }^{\S}$ Department of Economics, University of Glasgow, Glasgow, UK, Xiaoshan.Chen@glasgow.ac.uk, Tel. $+44(0) 1413304676$. Corresponding author.

†Department of Economics, University of Glasgow, Glasgow, UK, Alexandros.Kontonikas@glasgow.ac.uk, Tel. +44(0)1413306866

${ }^{\ddagger}$ Division of Economics, University of Stirling, Stirling, UK, alberto.montagnoli@stir.ac.uk, Tel. $+44(0) 1786467478$ 


\section{Introduction}

The severity of the recent financial crisis and the following deep recession has revived interest in the links between asset prices, credit market conditions and economic activity. Economic theory and empirical evidence suggest that developments in financial markets affect the aggregate demand through consumption wealth effects, investment balance sheet effects, and their impact on business confidence. During the boom period, higher credit availability boosts asset prices by expanding liquidity, and the private sector accumulates high levels of debt on the expectation of further rises in asset prices, whilst assets serve as collateral (see e.g. Bordo and Jeanne, 2002). When asset prices fall, the decline in the value of the collateral induces consumers to cut back expenditure and firms to reduce investment spending, leading to additional reductions in asset prices, bank lending and economic output. ${ }^{1}$

A number of recent empirical studies identify strong linkages between financial cycles and business cycles. These studies typically proceed in two steps: firstly, by utilising univariate techniques, such as the Hodrick-Prescott (HP) filter or the Harding and Pagan (2002) algorithm, to identify cyclical fluctuations in asset prices, credit and output; and subsequently by either employing correlation/regression analysis to examine the links between these cyclical components (see e.g. Claessens et al. 2011), or by adopting an event study approach (see e.g. Mendoza and Terrones (2008)). ${ }^{2}$ This approach, however, does not appropriately account for the endogenous nature of cycles in asset prices, credit and output. Another strand of the literature has utilised VAR analysis in order to deal with endogeneity. These studies typically utilise VAR systems including measures of asset prices (house and/or stock prices), credit, output and interest rates (see e.g. Gerlach and Peng, 2005; Goodhart and Hofmann, 2008).

In line with this previous literature, we estimate a system of five variables (real output, short-term interest rates, real house and stock prices, and credit). The novelty of this paper consists in the implementation of a multivariate unobserved components model containing the phase shift mechanism used by Runstler (2004) and Koopman and Azevedo

\footnotetext{
${ }^{1}$ See e.g. Bernanke and Gertler (1989) for a theoretical model with financial frictions which exhibits crucial interactions between asset prices, credit and economic activity.

${ }^{2}$ Having identified credit booms episodes, Mendoza and Terrones (2008) construct seven-year event windows around them to examine the behaviour of macroeconomic and financial indicators.
} 
(2008) to investigate feedback effects among monetary policy, credit conditions, asset valuations and real economic activity in the United States (US). Our approach allows us to simultaneously decompose the relevant series into trends and cyclical components at different frequencies (business and longer-term cycles) and accounts for the possibility of common trends and cycles. Therefore, compared with VAR based studies our approach identifies links between cyclical fluctuations in the raw (non-differenced) data at different frequencies and can reveal leading and lagging relationships. ${ }^{3}$ Furthermore, in relation to previous studies that examine the links between financial cycles and business cycles, we employ a multivariate structural time-series model that can avoid the potential distortions caused by the use of the HP (see e.g. Harvey and Jaeger, 1993, Cogley and Nason, 1995) and bandpass filters (see e.g. Murray, 2003). Finally, estimated model parameters can provide a more coherent and systematic measure of cyclical correlations.

The paper is structured as follows. Section 2 presents the model. Section 3 describes the dataset and empirical results. Section 4 concludes.

\section{Econometric framework}

Our basic model allows us to decompose $Y_{t}=\left[y_{t}, r_{t}, h p_{t}, s p_{t}, c_{t}\right]^{\prime}$ to vectors of trends $\left(\mu_{t}\right)$, cyclical components, which include short-cycles $\left(\psi_{1 t}\right)$ and long-cycles $\left(\psi_{2 t}\right)$, and irregular components $\left(\varepsilon_{t}\right)$ such that:

$$
Y_{t}=\mu_{t}+\psi_{1 t}+\psi_{2 t}+\varepsilon_{t}, \quad \varepsilon_{t} \backsim N I D\left(0, \Sigma_{\varepsilon}\right)
$$

where $y_{t}, r_{t}, h p_{t}, s p_{t}, c_{t}$ denote measures of real output, short-term interest rates, real house prices, real stock prices and credit, respectively.

The trend component intends to filter out low-frequency dynamics from the data and is modelled as multivariate random walk process:

$$
\mu_{t}=\mu_{t-1}+\beta+\eta_{t}, \quad \eta_{t} \backsim N I D\left(0, \Sigma_{\eta}\right) .
$$

The consideration of both short-cycles and long-cycles is consistent with Lucas and Koop-

\footnotetext{
${ }^{3}$ We would like to stress that our methodology uncovers potential leading and lagging relationships between the cyclical components of the series via the phase shift mechanism, but not in the usual Grangercausality sense.
} 
man (2005), and provides the best fit for our dataset. These cyclical components are modelled using the first-order trigonometric cycle specification introduced by Harvey and Jaeger (1993):

$$
\begin{gathered}
{\left[\begin{array}{c}
\psi_{i t} \\
\psi_{i t}^{*}
\end{array}\right]=\phi_{i}\left[\begin{array}{cc}
\cos \left(\lambda_{i}\right) I_{N} & \sin \left(\lambda_{i}\right) I_{N} \\
-\sin \left(\lambda_{i}\right) I_{N} & \cos \left(\lambda_{i}\right) I_{N}
\end{array}\right]\left[\begin{array}{l}
\psi_{i t-1} \\
\psi_{i t-1}^{*}
\end{array}\right]+\left[\begin{array}{l}
\kappa_{i t} \\
\kappa_{i t}^{*}
\end{array}\right],} \\
\operatorname{Var}\left[\begin{array}{c}
\kappa_{i t} \\
\kappa_{i t}^{*}
\end{array}\right]=\left[\begin{array}{cc}
\Sigma_{i \kappa} & 0 \\
0 & \Sigma_{i \kappa}
\end{array}\right],
\end{gathered}
$$

where $i=1,2$ and $N=5$. Both $\kappa_{i t}$ and $\kappa_{i t}^{*}$ are serially and mutually uncorrelated. The parameters $0 \leq \phi_{i}<1$ and $\lambda_{i}$ denote the damping factor and cycle frequency, respectively. The duration of the cycle is equal to $2 \pi / \lambda_{i}$

In order to account for the possibility of leading/lagging relationships between the cyclical components of the different economic and financial variables contained in our system, we include a phase shift mechanism (see also Runstler, 2004; Koopman and Azevedo, 2008) in Eq. (1):

$$
\begin{aligned}
Y_{t}= & \mu_{t}+\operatorname{diag}\left\{\cos \left(\lambda_{1} \xi\right)\right\} \psi_{1 t}+\operatorname{diag}\left\{\sin \left(\lambda_{1} \xi\right)\right\} \psi_{1 t}^{*} \\
& +\operatorname{diag}\left\{\cos \left(\lambda_{2} \zeta\right)\right\} \psi_{2 t}+\operatorname{diag}\left\{\sin \left(\lambda_{2} \zeta\right)\right\} \psi_{2 t}^{*}+\varepsilon_{t}
\end{aligned}
$$

where $\xi$ and $\zeta$ are $(5 \times 1)$ vectors:

$$
\begin{aligned}
\xi & =\left[\xi_{1}, \xi_{2}, \xi_{3}, \xi_{4}, \xi_{5}\right]^{\prime}, \\
\zeta & =\left[\zeta_{1}, \zeta_{2}, \zeta_{3}, \zeta_{4}, \zeta_{5}\right]^{\prime},
\end{aligned}
$$

The elements in $\xi$ and $\zeta$ measure the phase shifts between short-cycles and longcycles, respectively. In order to provide a clear interpretation of the leading and lagging relationships between cyclical components in the five time-series, we restrict the first elements, $\xi_{1}$ and $\zeta_{1}$, to zero. As real GDP is the first variable in the $Y_{t}$ vector, the short and long output cycles are used as the reference for the phase shifts of the remaining cycles in $\psi_{1 t}$ and $\psi_{2 t}$. The phase shift between the two short (long) cycles, $j$ and $k$, is 
calculated as $\xi_{j}-\xi_{k}\left(\zeta_{j}-\zeta_{k}\right)$ for $j, k=1, \ldots, 5$, with a positive value indicating that cycle $j$ leads cycle $k$, and vise versa, while a zero value implies that cycles are concurrent.

Cycles are related through their disturbances $\left(\kappa_{i t}\right)$ as implied by the variance-covariance matrix $\Sigma_{i \kappa}$ which can be expressed via the Cholesky decomposition:

$$
\Sigma_{i \kappa}=A_{i \kappa} D_{i \kappa} A_{i \kappa}^{\prime}
$$

If $\Sigma_{i \kappa}$ has full rank, all cycles have their own unique source of variance but may be still correlated with each other via the off-diagonal elements. However, if the rank of $\Sigma_{i \kappa}$ is less than full, common cyclical components exist. In this case, $A_{i \kappa}$ is a $\left(5 \times r_{i \kappa}\right)$ lower unity triangular matrix and $D_{i \kappa}$ is a $\left(r_{i k} \times r_{i \kappa}\right)$ diagonal matrix, where $r_{i \kappa}<5$. This rank-related principle also applies to the trend and irregular components.

Finally, as shown in Koopman and Azevedo (2008), the autocovariance function subject to phase shifts for $\psi_{i t}$ is defined as:

$$
\begin{aligned}
\Gamma(s) & =\phi_{i}^{|s|}\left(1-\phi_{i}^{2}\right)^{-1} \Sigma_{i \kappa} \odot \cos \left(\Lambda_{s}\right), \Lambda_{s}=\lambda\left(s \mathbf{1} \mathbf{1}^{\prime}+\mathbf{1} \xi^{\prime}-\xi \mathbf{1}^{\prime}\right), \\
s & =0,1,2 \ldots,
\end{aligned}
$$

where 1 is a vector $(1, \ldots 1)^{\prime}$.

We adopt the Bayesian approach to estimate the model parameters and the unobserved components. Following Creal et al. (2010), we select the priors on phase shift parameters to be a truncated normal distribution with the left and right truncation points equal to $\pm \frac{1}{2} \pi \lambda^{-1}$. A beta distribution is chosen for the cycle frequency parameters and a uniform prior for $\phi_{i}$ on the interval $[0,0.99)$ to ensure stationarity. The prior means and standard deviations on cycle parameters are reported in Table 2. In general, we use relative uninformative priors on the cycle parameters. By combining these prior distributions with the likelihood function evaluated using the Kalman filter, we obtain the posterior distribution of the parameters. ${ }^{4}$ A random walk Metropolis-Hastings algorithm is used to generate a million draws from the posterior distribution. We discarded the first 500,000 draws and take every 50th draw from the remaining 500,000 draws. Geweke

\footnotetext{
${ }^{4} \mathrm{We}$ set the variance of the proposal distribution equal to the scaled inverse Hessian obtained from the numerical maximisation. The scaling parameter is chosen to ensure an acceptance rate of $25 \%$ - $40 \%$.
} 
(1992) convergence diagnostics indicate that convergence is achieved. ${ }^{5}$

\section{Data and empirical results}

Quarterly data on the real GDP $\left(y_{t}\right)$, the effective federal funds rate $\left(r_{t}\right)$, real house prices $\left(h p_{t}\right)$, real stock prices $\left(s p_{t}\right)$ and total credit $\left(c_{t}\right)$ were collected for the US over the period 1965Q1-2010Q3. ${ }^{6}$

The three model selection criteria presented in Table 1 suggest that the common cycle and the phase shift specification is preferred by the data. Specifically, the preferred specification contains three short common cycles and four long common cycles, thereby indicating that the cyclical components are more correlated in the shorter-run. Table 2 report estimates of this model. The duration of the cycles is estimated to around 6 and 15 years for the short-run and the longer-run components, respectively. Therefore, the former (short-run cycle) corresponds to the business cycle frequency. The posterior means and standard deviations of the phase shifts provide stronger indication that cycles are not concurrent in the business cycle frequency, as opposed to the longer-run. Specifically, focusing on the business cycle frequency results, we find that output cycles tend to lead those in interest rates and credit, by around four quarters, thereby suggesting that developments in the real economy may be related to the future path of both the price and quantity of credit. Stock price cycles precede output cycles by around two quarters but the evidence is statistically weak. Finally, house price and output cycles appear to be concordant.

Tables 3 and 4 show the cross-correlations of the variables' cyclical components at the business cycle and longer-run frequency, respectively, implied by Eq. (6). The magnitude of the cross-sectional correlations shown in Tables 3 and 4 is consistent with the phase shift evidence in Table 2. For instance, as shown in Table 4, in the longer run all correlations are maximized (in absolute value) at $t=0$ in line with the findings that the phase shifts between longer cycles are statistically insignificant from zero.

\footnotetext{
${ }^{5}$ Geweke convergence diagnostics are available upon request.

${ }^{6}$ Real GDP is measured using billions of chained 2005 dollars. Stock prices are proxied by the S\&P 500 index. House prices are median sales prices for new houses sold in the US. Total credit is the sum of business (commercial and industrial), consumer and real estate loans at all commercial banks. Our source is the FRED database (http://research.stlouisfed.org/fred2/). Nominal asset prices and credit were converted into real terms using the consumer price index.
} 
We find that the longer-run output cycle is positively correlated with asset prices, while the longer-run cyclical component of interest rates is negatively correlated with that of both output and asset prices at all leads and lags. These findings are in line with the present value approach to asset pricing. At the business cycle frequency, we find that output and asset price cycles precede the interest rate cycle in a pro-cyclical fashion, while their lagged values are negatively correlated with the interest rate cycle. In addition, the house price (stock price) cycle appears to be more strongly correlated with output cycles in the business cycle (longer-run) frequency, potentially indicating that in the longer-run, other fundamentals, such as supply side factors, may also be important for property market developments. Furthermore, the correlation between stock and house price cyclical components is positive and much stronger in the business cycle frequency.

In the longer-run, the correlation between asset prices and credit cycles is positive both at leads and lags. This correlation evidence is consistent with the role of assets as collateral and with (positive) liquidity effects on asset prices from higher credit availability. At the business-cycle frequency, however, lagged asset price cycles are negatively correlated with the credit cycle. Finally, while in the longer-run credit and interest rate cycles are negatively correlated, in line with credit demand arguments, the business cycle frequency correlation is positive which may suggest that monetary policy tightens when credit booms.

Figures 1 and 2 plot the cyclical components of the variables at the business cycle and long-run frequency, respectively. In Figure 1 we can see that cyclical downturns in output at the business cycle frequency closely match the NBER recession periods. We can also observe that output cycles precede interest rates and credit cycles. Moreover, at the business cycle frequency, stock market upturns and downturns are much more severe than those in output, while house price and credit fluctuations are more aligned with the output cycle. On the other hand, as we can see in Figure 2, since the mid-1980s longer-run house price and credit booms and busts are more pronounced in comparison with output fluctuations. This suggests that credit and house prices have become more volatile during the period of financial liberalisation. 


\section{Conclusions}

This paper uses the multivariate unobserved components model with phase shifts to analyse the interaction among interest rates, output, asset prices and credit in the US. We find that in the longer run the cyclical components of these variables are concurrent and asset prices are consistent with the underlying fundamentals in line with the present value

approach to asset valuation. At the business cycle frequency, output and asset prices tend to lead interest rate and credit in a pro-cyclical fashion. 


\section{References}

Bernanke, B. and Gertler, M., 1989. Agency costs, net worth, and business fluctuations, American Economic Review, 79 (1), 14-31.

Bordo, M.D. and Jeanne, O., 2002. Boom-busts in asset prices, economic instability, and monetary policy, NBER Working Papers 8966, National Bureau of Economic Research, Inc.

Claessens, S., Kose, A., and Terrones, M.E., 2011. How do business and financial cycles interact?, CEPR Discussion Papers 8396, C.E.P.R. Discussion Papers.

Cogley, T. and Nason, J.M., 1995. Effects of the hodrick-prescott filter on trend and difference stationary time series implications for business cycle research, Journal of Economic Dynamics and Control, 19 (1-2), 253-278.

Creal, D., Koopman, S.J., and Zivot, E., 2010. Extracting a robust us business cycle using a time-varying multivariate model-based bandpass filter., Journal of Applied Econometrics, 25 (4), 695-719.

Gerlach, S. and Peng, W., 2005. Bank lending and property prices in Hong Kong, Journal of Banking and Finance, 29, 461-481.

Geweke, J., 1992. Bayesian Statistics, Oxford University Press, chap. Evaluating the accuracy of sampling-based approaches to calculating posterior moments.

Goodhart, C. and Hofmann, B., 2008. House prices, money, credit and the macroeconomy, Oxford Review of Economic Policy, 24 (1), 180-205.

Harding, D. and Pagan, A., 2002. Dissecting the cycle: a methodological investigation, Journal of Monetary Economics, 49 (2), 365-381.

Harvey, A.C. and Jaeger, A., 1993. Detrending, stylized facts and the business cycle, Journal of Applied Econometrics, 8 (3), 231-47.

Koopman, S.J. and Azevedo, J.V.E., 2008. Measuring synchronization and convergence of business cycles for the Euro area, UK and US, Oxford Bulletin of Economics and Statistics, 70 (1), 23-51. 
Lucas, A. and Koopman, S.J., 2005. Business and default cycles for credit risk, Journal of Applied Econometrics, 20 (2), 311-323.

Mendoza, E.G. and Terrones, M.E., 2008. An anatomy of credit booms: Evidence from macro aggregates and micro data, NBER Working Papers 14049, National Bureau of Economic Research, Inc.

Murray, C.J., 2003. Cyclical properties of baxter-king filtered time series, The Review of Economics and Statistics, 85 (2), 472-476.

Runstler, G., 2004. Modelling phase shifts among stochastic cycles, Econometrics Journal, 7 (1), 232-248. 
Table 1: Model comparison

\begin{tabular}{l|ccc}
\hline \hline Model & $\operatorname{lnML}$ & $\operatorname{lnL}$ & DIC \\
\hline No phase shift & -1880.776 & -1734.269 & 3569.234 \\
Phase shift & -1876.317 & -1716.997 & 3537.13 \\
Common cycle and phase shift & -1850.827 & -1706.784 & 3472.674 \\
\hline \hline
\end{tabular}

Notes: $\operatorname{lnML}, \operatorname{lnL}$ and DIC denote the log marginal likelihood, the log likelihood at mode and the deviance information criteria, respectively. The larger (smaller) the $\operatorname{lnML}, \operatorname{lnL}(\mathrm{DIC})$ the better the fit of the model.

Table 2: Phase shifts and cycles

\begin{tabular}{|c|c|c|c|c|c|c|c|c|}
\hline & \multicolumn{4}{|c|}{ Business Cycle } & \multicolumn{4}{|c|}{ Longer Cycle } \\
\hline & \multicolumn{2}{|c|}{$\begin{array}{l}\text { Prior } \xi_{j} \\
\text { mean } \quad \text { st.dev. }\end{array}$} & \multicolumn{2}{|c|}{$\begin{array}{l}\text { Posterior } \xi_{j} \\
\text { mean } \quad \text { st.dev. }\end{array}$} & \multicolumn{2}{|c|}{ Prior $\zeta_{j}$} & \multicolumn{2}{|c|}{ Posterior $\zeta_{j}$} \\
\hline$r_{t}$ & 0.00 & 2.50 & -4.050 & 0.912 & 0.00 & 2.50 & 0.653 & 2.446 \\
\hline$s p_{t}$ & 0.00 & 2.50 & 1.888 & 1.248 & 0.00 & 2.50 & 0.917 & 2.321 \\
\hline$h p_{t}$ & 0.00 & 2.50 & 0.121 & 0.936 & 0.00 & 2.50 & -0.360 & 2.374 \\
\hline$c_{t}$ & 0.00 & 2.50 & -4.052 & 0.918 & 0.00 & 2.50 & -0.568 & 2.382 \\
\hline & \multicolumn{2}{|c|}{ Prior $\phi_{1}$} & \multicolumn{2}{|c|}{ Posterior $\phi_{1}$} & \multicolumn{2}{|c|}{ Prior $\phi_{2}$} & \multicolumn{2}{|c|}{ Posterior $\phi_{2}$} \\
\hline & 0.50 & 0.20 & 0.962 & 0.012 & 0.50 & 0.20 & 0.983 & 0.006 \\
\hline & \multicolumn{2}{|c|}{ Prior $\lambda_{1}$} & \multicolumn{2}{|c|}{ Posterior $\lambda_{1}$} & \multicolumn{2}{|c|}{ Prior $\lambda_{2}$} & \multicolumn{2}{|c|}{ Posterior $\lambda_{2}$} \\
\hline & 0.314 & 0.10 & 0.256 & 0.022 & 0.157 & 0.10 & 0.100 & 0.012 \\
\hline
\end{tabular}

Notes: Phase shifts are measured in quarters.

Table 3: Cross-correlation for business cycles

\begin{tabular}{cccccccccccc}
\hline \hline$s$ & -6 & -4 & -3 & -2 & -1 & 0 & 1 & 2 & 3 & 4 & 6 \\
\hline$\psi_{1 t+s,}^{y}, \psi_{1 t}^{r}$ & 0.636 & 0.783 & $\mathbf{0 . 7 8 4}$ & 0.732 & 0.624 & 0.465 & 0.241 & 0.019 & -0.189 & -0.368 & -0.610 \\
$\psi_{1 t+s,}^{y}, \psi_{1 t}^{s p}$ & -0.283 & 0.045 & 0.230 & 0.415 & 0.586 & 0.730 & $\mathbf{0 . 7 7 3}$ & 0.763 & 0.704 & 0.605 & 0.324 \\
$\psi_{1 t+s,}^{y}, \psi_{1 t}^{h p}$ & 0.003 & 0.400 & 0.589 & 0.751 & 0.875 & $\mathbf{0 . 9 4 7}$ & 0.889 & 0.778 & 0.625 & 0.443 & 0.049 \\
$\psi_{1 t+s,}^{y}, \psi_{1 t}^{c}$ & 0.621 & 0.764 & $\mathbf{0 . 7 6 6}$ & 0.714 & 0.609 & 0.454 & 0.235 & 0.018 & -0.185 & -0.360 & -0.596 \\
$\psi_{1 t+s,}^{r}, \psi_{1 t}^{s p}$ & -0.625 & -0.560 & -0.463 & -0.326 & -0.155 & 0.040 & 0.230 & 0.390 & 0.514 & 0.596 & $\mathbf{0 . 6 2 7}$ \\
$\psi_{1 t+s,}^{r}, \psi_{1 t}^{h p}$ & -0.673 & -0.422 & -0.231 & -0.008 & 0.233 & 0.477 & 0.655 & 0.777 & 0.841 & $\mathbf{0 . 8 4 6}$ & 0.699 \\
$\psi_{1 t+s,}^{r}, \psi_{1 t}^{c}$ & 0.018 & 0.292 & 0.419 & 0.528 & 0.609 & $\mathbf{0 . 6 5 5}$ & 0.609 & 0.528 & 0.419 & 0.291 & 0.018 \\
$\psi_{1 t+s,}^{s p}, \psi_{1 t}^{h p}$ & 0.321 & 0.624 & 0.733 & 0.800 & $\mathbf{0 . 8 1 7}$ & 0.779 & 0.632 & 0.457 & 0.265 & 0.070 & -0.278 \\
$\psi_{1 t+s,}^{s p} \psi_{1 t}^{c}$ & $\mathbf{0 . 4 5 8}$ & 0.436 & 0.376 & 0.285 & 0.168 & 0.029 & -0.114 & -0.239 & -0.339 & -0.410 & -0.457 \\
$\psi_{1 t+s,}^{h p} \psi_{1 t}^{c}$ & 0.498 & $\mathbf{0 . 6 0 3}$ & 0.599 & 0.553 & 0.466 & 0.339 & 0.165 & -0.006 & -0.165 & -0.300 & -0.480 \\
\hline \hline
\end{tabular}

Notes: $s$ denotes the number of leads $(s<0)$ and lags $(s>0)$ in quarters of the first variable with respect to the second variable in the first column. Bold indicates the highest correlation (in absolute value). 
Table 4: Cross-correlation for long cycles

\begin{tabular}{cccccccccccc}
\hline \hline$s$ & -12 & -8 & -6 & -4 & -1 & 0 & 1 & 4 & 6 & 8 & 12 \\
\hline$\psi_{2 t+s}^{y}, \psi_{2 t}^{r}$ & -0.181 & -0.418 & -0.525 & -0.617 & -0.717 & $\mathbf{- 0 . 7 3 8}$ & -0.727 & -0.652 & -0.574 & -0.479 & -0.254 \\
$\psi_{2 t+s}^{y}, \psi_{2 t}^{s p}$ & 0.186 & 0.454 & 0.576 & 0.683 & 0.800 & $\mathbf{0 . 8 2 6}$ & 0.815 & 0.738 & 0.654 & 0.549 & 0.301 \\
$\psi_{2 t+s,}^{y} \psi_{2 t}^{h p}$ & 0.109 & 0.212 & 0.257 & 0.294 & 0.331 & $\mathbf{0 . 3 3 7}$ & 0.328 & 0.285 & 0.245 & 0.197 & 0.090 \\
$\psi_{2 t+s,}^{y}, \psi_{2 t}^{c}$ & 0.241 & 0.459 & 0.552 & 0.628 & 0.702 & $\mathbf{0 . 7 1 3}$ & 0.694 & 0.599 & 0.511 & 0.408 & 0.180 \\
$\psi_{2 t+s}^{r}, \psi_{2 t}^{s p}$ & -0.155 & -0.334 & -0.413 & -0.481 & -0.551 & $\mathbf{- 0 . 5 6 5}$ & -0.554 & -0.492 & -0.429 & -0.353 & -0.178 \\
$\psi_{2 t+s,}^{r} \psi_{2 t}^{h p}$ & -0.076 & -0.138 & -0.164 & -0.184 & -0.203 & $\mathbf{- 0 . 2 0 5}$ & -0.199 & -0.169 & -0.142 & -0.112 & -0.045 \\
$\psi_{2 t+s,}^{r}, \psi_{2 t}^{c}$ & -0.196 & -0.345 & -0.407 & -0.456 & -0.499 & $\mathbf{- 0 . 5 0 4}$ & -0.487 & -0.411 & -0.344 & -0.267 & -0.102 \\
$\psi_{2 t+s,}^{s p} \psi_{2 t}^{h p}$ & 0.129 & 0.226 & 0.266 & 0.298 & 0.325 & $\mathbf{0 . 3 2 8}$ & 0.317 & 0.267 & 0.223 & 0.173 & 0.065 \\
$\psi_{2 t+s,}^{s p}, \psi_{2 t}^{c}$ & 0.355 & 0.609 & 0.713 & 0.794 & 0.862 & $\mathbf{0 . 8 6 8}$ & 0.837 & 0.700 & 0.580 & 0.446 & 0.158 \\
$\psi_{2 t+s,}^{h p} \psi_{2 t}^{c}$ & 0.227 & 0.454 & 0.553 & 0.635 & 0.717 & $\mathbf{0 . 7 3 2}$ & 0.714 & 0.624 & 0.537 & 0.435 & 0.204 \\
\hline \hline
\end{tabular}

Notes: See Table 3 Notes. 
Figure 1: Business cycle components
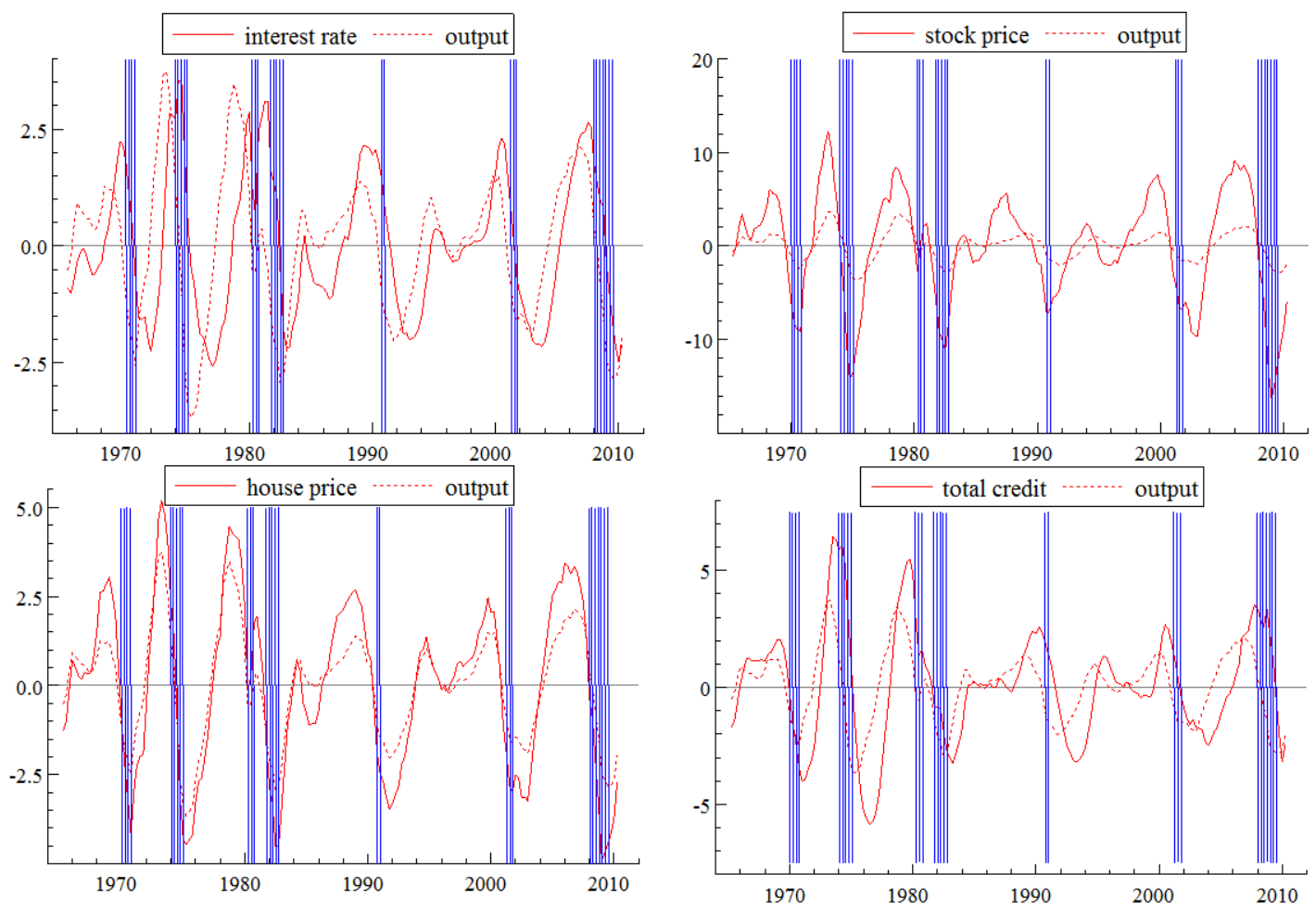

Notes: Shaded areas correspond to NBER recession periods. 
Figure 2: Long-term cycle components
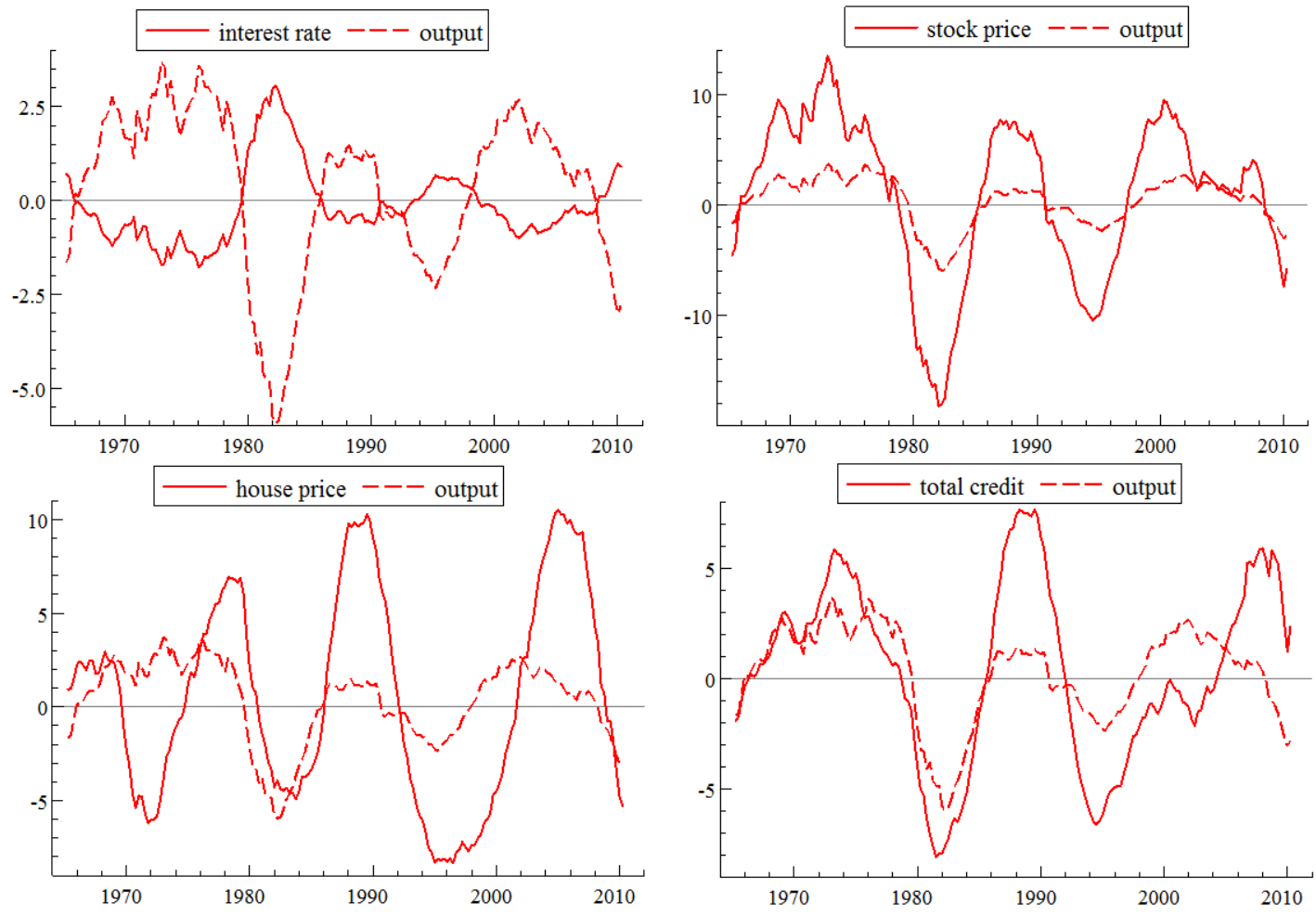